\title{
Effect of phacoemulsification on corneal endothelium in type 1 and type 2 diabetes mellitus
}

\author{
Tarek Abdel Razik, Amr Said
}

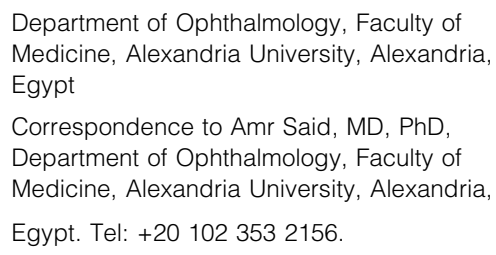

Department of Ophthalmology, Faculty of Medicine, Alexandria University, Alexandria, Egypt

Correspondence to Amr Said, MD, PhD, Department of Ophthalmology, Faculty of Medicine, Alexandria University, Alexandria, Egypt. Tel: +20 1023532156

Zip Code: $21500 \quad$ Fax: 01023532156

E-mail:docamro1@gmail.com

Received: October 2019

Revised: October 2019

Accepted: November 2019

The Egyptian Journal of Cataract and Refractive Surgery 2019

\begin{abstract}
Purpose
The aim of this study is to compare the effect of phacoemulsification on cornealendothelium in type 1 and 2 of diabetes mellitus (DM).

Patients and methods

This study is a retrospective, interventional, comparative study that included 400 eyes of 320 patients with DM and with visually significant cataract. The patientswere divided into two equal groups: one group with type 1 and the other with type 2DM. Specular microscopy assessing the endothelial cell count was done before surgery and after it 1 and 3 months in both groups. Results

The two groups were highly comparable to each other regarding the mean age, axial length, manifest refraction, and endothelial cell count. Postoperatively, therewas a statistically significant difference between the two groups regarding the endothelial cell count. Both groups had endothelial cell loss from mean of 2150-1879 in type 1 DM group and from 2213 to1995 in type 2 DM group. The endothelial cell loss was more in type 1 DM group than in type 2DM $(P<0.005)$.

Conclusion

Phacoemulsification produces endothelial cell loss in diabetic patients more in type 1 than in type 2 DM.
\end{abstract}

Keywords:

Catarct, endothelium, dibetes, phacoemulsification, IOL

\section{Introduction}

Phacoemulsification is one of the most commonly performed surgery with an estimated 19 million operations performed annually worldwide [1]. The WHO states that this number will increase to 32 million by 2020 [2] as the over-65-year-old population worldwide is expected to double between 2000 and 2020 [3]. One of the main concerns during phacoemulsification is the effect of ultrasound energy on corneal endothelium especially in the harder nucleus cases [4]. With modern phacosurgery, the use of more vacuum and less energy with application of torsional rather than longitudinal together with the advances in the field of ocular viscoelastic materials provided a less hazardous effect on various ocular structures, namely the endothelium [5-7]. However, endothelial cell loss is still a concern for cataract surgeons especially in cases with vulnerable endothelium as in the presence of corneal guttata and in diabetic patients $[8,9]$. The diabetic cornea suffers from endothelium cellular dysfunction and dysfunctional repair mechanisms due to hyperglycemia-induced increase in aldose reductase activity with expression matrix metalloproteinases [10]. Metalloproteinases can damage the basement membrane and limit cellular migration of the endothelium, resulting in poor healing. This makes the cornea of diabetic patients more vulnerable to stress and trauma than in nondiabetics [11].

Proved in some studies to affect more than $20 \%$ of diabetic patients, the effect of the type of diabetes, duration, and control on the outcome of cataract surgery becomes of paramount importance among cataract surgeons [12].

The aim of this study was to compare endothelial cell changes following straightforward phacoemulsification in diabetic patients with type 1 and 2 diabetes mellitus (DM).

\section{Patients and methods}

A retrospective analysis was conducted on records of patients operated by the same surgeon (T.A.R.) for cataract surgery and intraocular lens (IOL) implantation and having DM either of type 1 or type 2 during the period from January 2014 till January 2019 at Alex Eye Center, Alexandria,

\footnotetext{
This is an open access journal, and articles are distributed under the terms of the Creative Commons Attribution-NonCommercial-ShareAlike 4.0 License, which allows others to remix, tweak, and build upon the work non-commercially, as long as appropriate credit is given and the new creations are licensed under the identical terms.
} 
Egypt. Written informed consent was obtained from each participant in concordance with Declaration of Helsinki. Ethics Committee at Faculty of Medicine, Alexandria University approved this study. All procedures performed in studies involving human participants were in accordance with the ethical standards of the research committee.

Cataract removal surgery was done for a total of 320 eyes of 400 patients after obtaining informed consent from the patients. Cases of macular scars and glaucoma were excluded from the study. Patients with poor glycemic control at the time of surgery (glycosylated hemoglobin $>7$ ) were also excluded.

Preoperative examinations were conducted for cataract density, keratometry, axial lengths, posterior segment abnormalities, intraocular pressure, and systemic disorders. Baseline endothelial characteristics were evaluated using specular microscopy.

IOL power calculation was performed in all cases usingoptical biometry (IOL-master; Carl Zeiss, Germany)with theoretical formula SRK-T.Carl Zeiss Meditech Inc., Dublin, California, USA

The patients were distributed into two groups. First group had type $1 \mathrm{DM}$ while group 2 with type $2 \mathrm{DM}$.

Corneal incisions were created using a $2.4 \mathrm{~mm}$ keratome blade for the main incision placed in all cases on the steep topographic axis as determined using corneal topography and $1.2 \mathrm{~mm}$ blade for the side ports. The anterior chamber was filled with viscoelastic. Continuous curvilinear capsulorhexis was created with a capsulorhexis forceps. Lens segmentation was performed using a divide-and-conquer approach.

Infinity Phacoemulsification System (Alcon, USA) was used in all cases. Effective phaco time was calculated in each patient. Patients with intraoperative complications such as vitreous loss, dropped lens matter into the posterior segment, or lens capsule subluxation were excluded from the study. The procedure was followed by IOL implantation in the capsular bag after removal of the lens cortex: Tecnis-1 aspheric IOL (Advanced Medical Optics) using its injector provided by the company. Careful removal of viscoelastic material from the anterior chamber was carried out in all cases followed by careful stromal hydration of all corneal wound. Postoperative antibiotic and steroid eye drops were prescribed for 1 week followed which antibiotic eye drops were stopped, while gradual withdrawal of steroid eye drops was performed along 3 weeks.
All cases were followed after 1 day and then after 1 week, 1 month, and 3 months. Visual acuity and refraction were measured during all follow-up visits. Specular microscopy was performed during 1 and 3 months only. Mean absolute error (MAE) and manifest refraction spherical equivalent (MRSE) were calculated at both follow-up periods in each group.

\section{Statistical analysis}

The data were entered into an Excel spreadsheet (Microsoft Corp., Redmond, Washington, USA). It was converted into a spreadsheet for Statistical Package for Social Studies (SPSS, version 23 for Windows). SPSS for windows Version 19 (IBM/SPSS Inc., Chicago, Illinois, USA).

Quantitative data were described using range, mean, and SD. Comparison between different periods was assessed using paired $t$ test for comparisons between the preoperative and postoperative data. To compare between both groups if they are normally distributed, independent sample $t$ test was used. The Mann-Whitney $U$ test was applied to assess the significance of such differences when parametric analysis was not possible (in values that are not normally distributed according to Kolmogorov-Smirnov test for normality of distribution).

Percentages of endothelial cell loss in both groups were calculated. $c^{2}$ test was used to compare between both groups regarding different percentages. Differences were considered to be statistically significant when the associated $P$ value was less than 0.05 at $95 \%$ confidence interval.

\section{Results}

The current study was a retrospective comparative analysis of the records of 400 eyes of 320 diabetic patients with visually significant cataract affecting the quality of life. Table 1 shows the demographic and preoperative characteristics of the included patients. There was no statistically significant difference between the two groups regarding preoperative characteristics. The two groups were highly comparable to each other regarding the mean age, axial length, manifest refraction, and preoperative endothelial cell count as measured using specular microscopy. None of the eyes reached 20/20 of corrected distance visual acuity (CDVA), and the worst CDVA was 20/125. Subgroup analysis of the right eye or the left eye alone did not show any different results.

Table 2 shows the visual acuity [uncorrected distance visual acuity (UDVA) and CDVA], endothelial cell count, and manifest refraction along the postoperative 
Table 1 Preoperative characteristics of the included eyes (400 eyes) of $\mathbf{3 2 0}$ patients who were divided equally into two groups

\begin{tabular}{lccc}
\hline & $\begin{array}{c}\text { Type 1 DM }(N=200) \\
{[\text { mean } \pm \text { SD (range) }}\end{array}$ & $\begin{array}{c}\text { Type 2 DM }(N=200) \\
{[\text { mean } \pm \text { SD (range) }}\end{array}$ & $\begin{array}{c}P \\
\text { value }\end{array}$ \\
\hline $\begin{array}{l}\text { Male : } \\
\text { female }\end{array}$ & $7: 10$ & $6: 10$ & $0.464^{\mathrm{a}}$ \\
$\begin{array}{l}\text { Age } \\
\text { (years) }\end{array}$ & $62.7 \pm 4.1$ & $62.2 \pm 3.5$ & $0.781^{\mathrm{b}}$ \\
$\begin{array}{l}\text { ECC } \\
(\text { cell/ }\end{array}$ & $2150 \pm 13.1$ & $2213 \pm 23.1$ & $0.645^{\mathrm{b}}$ \\
$\left.\mathrm{mm}^{2}\right)$ & $2.52 \pm 2.3$ & $2.57 \pm 2.5$ & $0.925^{\mathrm{b}}$ \\
MRSE & $0.43 \pm 0.15$ & $0.45 \pm 0.16$ & $0.638^{\mathrm{b}}$ \\
CDVA & $22.6 \pm 1.2$ & $22.7 \pm 1.2$ & $0.854^{\mathrm{b}}$ \\
\hline AL $(\mathrm{mm})$ & & &
\end{tabular}

$\mathrm{AL}$, axial length; CDVA, corrected distance visual acuity; DM, diabetes mellitus; ECC, endothelial cell count; MRSE, manifest refraction spherical equivalent. ${ }^{\mathrm{a}} \chi^{2}$ test. ${ }^{\mathrm{b}}$ Independent sample $t$ test.

Table 2 Visual acuity, refraction, and endothelial cell count along the postoperative follow-up period

\begin{tabular}{lcc}
\hline Mean \pm SD (range) & 1 month & 3 months \\
\hline Type 1 DM: UDVA & $0.73 \pm 0.34$ & $0.70 \pm 0.32$ \\
Type 2 DM: UDVA & $0.43 \pm 0.22$ & $0.41 \pm 0.19$ \\
$P$ value & 0.005 & 0.003 \\
Type 1 DM: CDVA & $0.44 \pm 0.19$ & $0.41 \pm 0.16$ \\
Type 2 DM: CDVA & $0.42 \pm 0.20$ & $0.40 \pm 0.18$ \\
$P$ value & 0.647 & 0.728 \\
Type 1 DM: ECC & $1879 \pm 33.1$ & $1810 \pm 11.8$ \\
Type 2 DM: ECC & $1995 \pm 21.6$ & $1945 \pm 21.5$ \\
Type 1 DM: MRSE & $1.11 \pm 1.32$ & $1.01 \pm 1.26$ \\
Type 2 DM: MRSE & $0.12 \pm 0.72$ & $0.09 \pm 0.69$ \\
$P$ value & 0.024 & 0.029 \\
Type 1 DM: MAE & $0.42 \pm 1.06$ & $0.39 \pm 0.93$ \\
& & $0.52 \pm 0.43$ \\
Type 2 DM: MAE (D) & $0.55 \pm 0.46$ & 0.007 \\
$P$ value & 0.009 &
\end{tabular}

CDVA, corrected distance visual acuity; DM, diabetes mellitus; $M A E$, mean absolute error; MRSE, manifest refraction spherical equivalent; UDVA, uncorrected distance visual acuity. $P$ value: compares mean of primary piggyback versus secondary Artisan using independent sample $t$ test. *Statistically significant.

follow-up period. There was a statistically significant difference between the two groups regarding the UDVA, CDVA, and endothelial cell count. Both were less in patients with type $1 \mathrm{DM}$. MAE and MRSE show no statistically significant differences between both groups. Using paired $t$ test to compare mean UDVA, CDVA, endothelial cell count, MAE, and MRSE at 1 and 3 months, there was no statistically significant difference. Endothelial cell count dropped with statistically significant difference in both groups at the first month of follow-up in comparison to the preoperative values with further drop at 3 months of follow-up that was not statistically significant. The mean CDVA at 1 and 3 months improved in comparison with preoperative levels for both groups.

\section{Discussion}

Several studies have been conducted to evaluate the effect of various techniques of cataract surgery on the corneal endothelium. All these studies have shown a decline in the endothelial status after surgery $[13,14]$. However, there are only a few studies which have compared these changes in patients with diabetes. Al-Sharkawy had conducted a similar study on 100 eyes of 99 patients (49 with and 50 without type 2 diabetes) with senile cataract who underwent phacoemulsification with foldable IOL implantation. Specular microscopy was performed preoperatively, at 1 week and at 3 months postoperatively to evaluate endothelial cell density, coefficient of variation (CV), and central corneal thickness (CCT). Although no significant difference was found in ECL following phacoemulsification between the two groups, diabetic patients had a significantly greater increase in $\mathrm{CV}$ (polymegathism) and CCT compared with nondiabetic patients. Al-Sharkawy disagrees with our study in comparison between nondiabetic and diabetic groups in terms of the difference between preoperative and postoperative CCT but in terms of endothelial cell loss as it was significant in our study [15]. Wojciechowska et al. [16] found no statistically significant differences in corneal endothelial changes after extracapsular cataract extraction with posterior chamber IOL implantation between nondiabetic and diabetic patients. Lee et al. [17] investigated the differences in corneal endothelial cell morphology between diabetic patients who were divided by the degree of severity of diabetic retinopathy and normal patients after phacoemulsification with IOL implantation and concluded that corneal endothelial cell density decreased and the $\mathrm{CV}$ in cell size increased for high-risk proliferative diabetic retinopathy patients undergoing phacoemulsification, in contrast to normal persons at 6 months postoperatively. Although the exact explanation for the discrepancy between the results of the present study and others is difficult to determine, one possible reason may be that the diabetic conditions, particularly blood glucose levels and duration of disease, was different in the various studies.

Khan and colleagues had a similar study conducted on 66 cataract patients, out of which 33 patients were with 
DM and 33 without DM (type 2). After phacoemulsification, all cases were followed up on first day, first week, 1 month, and 3 months; and UDVA, best-corrected visual acuity, corneal thickness, endothelial cell count, and morphometric analysis were recorded. At the end of 3 months, it was found that the mean endothelial cell loss in group A (diabetic) was $6.9 \pm 0.6 \%$ and in group B (control) was $2.4 \pm 0.3 \%$. In Khan's study the mean endothelial cell loss in diabetic patients is less than in our study; however, it was still statistically significant as in our study [18].Our study has some limitations. Being retrospective in nature makes the study liable to be affected by confounding factors. Also, lack of control group of nondiabetic patients may be another source of criticism. No available data were found in the reports regarding other endothelial cell characters rather than cell count such as the percentage of hexagonal cells and $\mathrm{CV}$.

\section{Acknowledgements}

Data availability: ?data used to support the findings of this study are available from the corresponding author on request.

\section{Financial support and sponsorship}

Nil.

\section{Conflicts of interest}

None declared.

Authors have no financial interest in any of materials or devices used

\section{References}

1 Gupta D, Taravati P. Effect of surgical case order on cataract surgery complication rates and procedure time. J Cataract Refract Surg 2015; 41:594-597.

2 Koopman S. Cataract surgery devices. Global pipeline analysis, competitive landscape and market orecasts to 2017. Available at: www. asdreports.com/news.asp?pr_id=261. [Accessed January 30, 2017].
3 Fubini S. A collective vision of health care in the year 2020. Nutrition 1997; 13:62-63.

4 Wilczynski M, Supady E, Loba P, Synder A, Palenga-Pydyn D, Omulecki W. Comparison of early corneal endothelial cell loss after coaxial phacoemulsification through $1.8 \mathrm{~mm}$ microincision and bimanual phacoemulsification through $1.7 \mathrm{~mm}$ microincision. J Cataract Refract Surg 2009; 35:1570-1574.

5 Bozkurt E, Bayraktar S, Yazgan S, Cakir M, Cekiç O, Erdogan H, Yilmaz OF. Comparison of conventional and torsional mode (OZil) phacoemulsification: randomized prospective clinical study. Eur J Ophthalmol 2009; 19:984-989.

6 Schmutz JS, Olson RJ. Thermal comparison of Infiniti OZil and Signature Ellips phacoemulsification systems. Am J Ophthalmol 2010; 149:762-767.

7 Schulze SD, Bertelmann T, Manojlovic I, Bodanowitz S, Irle S, Sekundo W. Changes in corneal endothelium cell characteristics after cataract surgery with and without use of viscoelastic substances during intraocular lens implantation. Clin Ophthalmol 2015; 9:2073-2080.

8 Choi JH, Oh HJ, Yoon KC. Long-term results after cataract surgery in patients with low corneal endothelial cell density. J Korean Ophthalmol Soc 2013; 54:602-609.

9 Kim P, Jung MS. Influence of preoperative corneal endothelial status on postoperative corneal endothelium density after cataract surgery. J Korean Ophthalmol Soc 2017; 58:131-139.

10 Lutty GA. Effects of diabetes on the eye. Investig Ophthalmol Vis Sci 2013; 54:Orsf81-Orsf87.

11 Datiles MB, Kador PF, Kashima K, Kinoshita JH, Sinha A. The effects of sorbinil, an aldose reductase inhibitor, on the corneal endothelium in galactosemic dogs. Investig Ophthalmol Vis Sci 1990; 31:2201-2204.

12 Gary M, Keoleian XX, John M, Pach XX, David O, Hodge B, et al. Structural and functional studies of the corneal endothelium in diabetes mellitus. Am J Ophthalmol 1992; 113:64-70.

13 Walkow T, Anders N, Klebe S. Endothelial cell loss after phacoemulsification: relation to preoperative and intraoperative parameters. J Cataract Refract Surg 2000; 26:727-732.

14 Dick HB, Kohnen T, Jacobi FK, Jacobi KW. Long-term endothelial cell loss following phacoemulsification through a temporal clear corneal incision. $\mathrm{J}$ Cataract Refract Surg 1996; 22:63-71.

15 Al-Sharkawy HT. Corneal endothelial changes in type 2 diabetes mellitus before and after cataract surgery. J Egypt Ophthalmol Soc 2015; $108: 79$

16 Wojciechowska R, Bolek S, Janiec S. Corneal endothelium in patients with diabetes after extracapsular cataract extraction with intraocular lens implantation in the posterior chamber. Klin Oczna 1995; 97:221-222.

17 Lee JS, Lee JE, Choi HY, Oum BS, Cho BM. Corneal endothelial cell change after phacoemulsi cation relative to the severity of diabetic retinopathy. J Cataract Refract Surg 2005; 31:742-749.

18 Khan A, Kose S, Jharwal MK, Meena A, Sharma A. Comparison of corneal endothelial cell counts in patients with controlled diabetes mellitus (type 2) and non diabetics after phacoemulsification and intraocular lens implantation. Int Multispec J Health 2016; 2:2395-6291. 